\title{
Colony-Stimulating Factor-1-Responsive Macrophage Precursors Reside in the Amphibian (Xenopus laevis) Bone Marrow rather than the Hematopoietic Subcapsular Liver
}

\author{
Leon Grayfer Jacques Robert \\ Department of Microbiology and Immunology, School of Medicine and Dentistry, University of Rochester Medical \\ Center, Rochester, N.Y., USA
}

\section{Key Words}

Amphibians · Colony-stimulating factor- $1 \cdot$ Hematopoiesis .

Macrophages · Monopoiesis · Myelopoiesis · Xenopus

\begin{abstract}
Macrophage precursors originate from and undergo lineage commitment within designated sites of hematopoiesis, such as the mammalian bone marrow. These cells subsequently differentiate in response to stimulation with macrophage colony-stimulating factor-1 (CSF-1). The amphibian bone marrow, unlike that of mammals, has been overlooked as a source of leukocyte precursors in favor of the liver subcapsular region, where hematopoiesis occurs in anurans. Here we report that the bone marrow rather than the liver periphery provides macrophage progenitors to the amphibian Xenopus laevis. We identified the amphibian CSF-1, examined its gene expression in developing and virally infected $X$. lae-

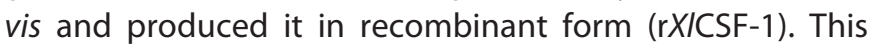
rXICSF-1 did not bind or elicit proliferation/differentiation of subcapsular liver cells. Surprisingly, a subpopulation of bone marrow cells engaged this growth factor and formed rXICSF-1 concentration-dependent colonies in semisolid medium. Furthermore, rXICSF-1-treated bone marrow (but not liver) cultures comprised of cells with characteristic macrophage morphology and high gene expression of the mac-
\end{abstract}

rophage marker CSF-1 receptor. Together, our findings indicate that in contrast to all other vertebrates studied to date, committed Xenopus macrophage precursor populations are not present at the central site of hematopoiesis, but reside in the bone marrow.

Copyright $\odot 2013$ S. Karger AG, Basel

\section{Introduction}

Macrophage lineage cells are indispensable to vertebrate host immunity and homeostasis. While the developmental pathways governing the production of mononuclear phagocytes are complex and poorly understood, it is well established that colony-stimulating factor-1 (CSF-1), or macrophage-CSF (M-CSF), is the principal molecule responsible for the development, differentiation, proliferation and survival of these cell lineages across all vertebrate species examined to date [1-4].

The functional form of CSF-1 is a homodimer, which ligates the $\mathrm{c}-\mathrm{fms}$ proto-oncogene product, the CSF-1 receptor (CSF-1R) [5]. CSF-1R cell surface expression is restricted primarily to committed macrophage precursors and their progeny cells $[6,7]$, dictating the specificity of CSF-1 function.

\section{KARGER}

(c) 2013 S. Karger AG, Basel

1662-811X/13/0056-0531\$38.00/0

E-Mail karger@karger.com

www.karger.com/jin 
Committed macrophage precursors of vertebrate species originate and reside in designated hematopoietic sites. In birds and mammals, these cells arise from the bone marrow pluripotent populations $[4,8,9]$ whereas in bony fish they emerge in the head kidney $[10,11]$. In anurans such as Xenopus spp., the subcapsular (peripheral) zone of the liver functions as the site of hematopoiesis [12-15], while the Xenopus bone marrow is relatively rudimentary and thought to serve only as the site of granulocyte differentiation/storage $[13,14]$.

Here we report the first discovery of an anuran CSF-1, the production of a recombinant form of this $X$. laevis macrophage growth factor ( $\mathrm{rXlCSF}-1)$ and the utilization of $\mathrm{rXlCSF}-1$ to identify and differentiate Xenopus macrophage precursors. While the liver periphery serves as the central site of hematopoiesis in this species, it does not appear to possess cells capable of binding, proliferating or differentiating in response to $\mathrm{rXlCSF}-1$. In contrast and to our surprise, the $X$. laevis bone marrow contained cell population(s) that bound $\mathrm{rXlCSF}-1$. Upon in vitro culture with $\mathrm{rXlCSF}-1, \mathrm{X}$. laevis bone marrow cells formed colonies in semisolid medium and differentiated into cells with classic macrophage morphology and high CSF-1R expression. Our findings indicate that in contrast to other vertebrates, committed Xenopus macrophage populations are not present at the primary hematopoietic site of the subcapsular liver, but are found in the rudimentary bone marrow.

\section{Materials and Methods}

\section{Animals}

Outbred premetamorphic (stage 54-56) tadpoles, and metamorphic (stage 64) and adult (2-year-old) frogs were obtained from our X. laevis research resource for immunology at the University of Rochester (http://www.urmc.rochester.edu/smd/mbi/ xenopus/index.htm). All animals were handled under strict laboratory and UCAR regulations (approval No. 100577/2003-151).

\section{Identification of X. tropicalis CSF-1, X. laevis CSF-1 and CSF-1R}

Gene synteny analysis was performed using the server of the National Center for Biotechnology Information, MapViewer option. The CSF-1 loci of the human (Homo sapiens, chromosome 1), mouse (Mus musculus, chromosome 3) and green anole (Anolis carolinensis, chromosome 4) were compared. The conserved genes syntenic to CSF-1 were located in the X. (Silurana) tropicalis genome (gene scaffold NW_003163367.1) and found to flank a putative CSF-1 gene. Partial X. laevis CSF-1 cDNA was identified using primers against the $X$. tropicalis CSF-1. RACE PCR was performed in accordance with manufacturer directions (Clonetech) to identify the $5^{\prime}$ and $3^{\prime}$ regions of the $X$. laevis cDNA transcript (accession No. JX418294). The partial CSF-1R cDNA (accession
No. JX418295) was identified by methods described for CSF-1. All sequences of primers used are listed in the online supplementary table 1 (for all online suppl. material, see www. karger.com/doi/10.1159/000346928).

\section{In silico Analyses}

Protein sequence alignments were performed using the Clustal W software (http://www.ebi.ac.uk/clustalw/). Signal peptide regions were identified using the SignalP 3.0 server (http://www.cbs. $\mathrm{dtu}$.dk/services/SignalP/) and the transmembrane regions predicted using the TMHMM server v. 2.0 (http://www.cbs.dtu.dk/ services/TMHMM/). Phylogenetic analysis was performed by Clustal X software using the neighbor-joining method and bootstrapped 10,000 times, with values expressed as percentages.

\section{Frog Virus 3 Stocks and Animal Infections}

FMH (fathead minnow cells; American Type Culture Collection No. CCL-42) were maintained in DMEM (Invitrogen) supplemented with $10 \%$ fetal bovine serum (Invitrogen), penicillin (100 $\mathrm{U} / \mathrm{ml})$ and streptomycin $(100 \mu \mathrm{g} / \mathrm{ml})$ with $5 \% \mathrm{CO}_{2}$ at $37^{\circ} \mathrm{C} . \mathrm{FV} 3$ (frog virus 3 ) was grown by a single passage on FMH cells, purified by ultracentrifugation on a $30 \%$ sucrose cushion and quantified by plaque assay on FMH monolayer under an overlay of 1\% methylcellulose [16].

Animals were infected by intraperitoneal injections with $5 \times$ $10^{6}$ plaque-forming units of FV3 in $100-\mu$ l volumes. Three days after infection, frogs were euthanized by immersion in $0.5 \%$ tricaine methane sulfonate (MS-222), and tissues removed and processed for RNA isolation.

\section{Semiquantitative (RT) and Quantitative PCR Gene}

Expression Analysis

Total RNA and DNA were extracted from frog tissues using the TRIzol reagent following the manufacturer directions (Invitrogen). All cDNA synthesis was performed using the iScript cDNA synthesis kit according to manufacturer directions (Bio-Rad) using $500 \mathrm{ng}$ of total DNAse-treated (Ambion) RNA. One microliter of these respective synthesized cDNA samples or $50 \mathrm{ng}$ of total isolated DNA were used as templates for RT-PCR analysis. PCR products were resolved on $1.5 \%$ agarose gels, visualized with ethidium bromide and compared against a $1 \mathrm{~kb}$ plus DNA marker (Invitrogen).

Quantitative PCR gene expression analysis was performed using the $\triangle \triangle C T$ method using the ABI 7300 real-time PCR system and PerfeCTa ${ }^{\circledR}$ SYBR Green FastMix, ROX (Quanta). Expression analysis of the $X$. laevis CSF-1 and CSF-1R was performed relative to the GAPDH endogenous control and normalized against the lowest observed expression (tadpole muscle, $\mathrm{n}=3$; fresh bone marrow cells, $n=6$ ). Quantitative PCR analysis of FV3-infected animals was performed using kidney and bone marrow tissues from 6 adult frogs and spleen and liver tissues from 3 animals and normalized against the healthy kidney expression. Expression analysis was performed using ABI sequence detection system software. All primers were validated prior to use. Primer sequences are listed in the online supplementary table 1.

\section{Production of rXlCSF-1}

The portion of the $X$. laevis CSF-1 sequence representing the signal peptide-cleaved, extracellular fragment was ligated into the pMIB/V5 His A insect expression vector (Invitrogen) and intro- 
duced into Sf9 insect cells (cellfectin II, Invitrogen). Transfected Sf9 supernatants were confirmed to express the $\mathrm{rXlCSF}$-1, positive transfectants were selected using $10 \mu \mathrm{g} / \mathrm{ml}$ blasticidin, scaled up into 500-ml liquid cultures and grown for 5 days. Cultures were pelleted, supernatants were removed and dialyzed overnight at $4^{\circ} \mathrm{C}$ against $150 \mathrm{mM}$ sodium phosphate, concentrated against polyethylene glycol flakes $(8 \mathrm{kDa})$ at $4{ }^{\circ} \mathrm{C}$, dialyzed overnight at $4{ }^{\circ} \mathrm{C}$ against $150 \mathrm{~mm}$ sodium phosphate and passed through an Ni-NTA agarose column (Qiagen) to bind the rXICSF-1. The column was washed $2 \times$ with 10 volumes of high-stringency wash buffer $(0.5 \%$ Tween 20; $50 \mathrm{~mm}$ sodium phosphate; $500 \mathrm{~mm}$ sodium chloride; $100 \mathrm{~mm}$ imidazole) and $5 \times$ with low-stringency wash buffer (as above, but with $40 \mathrm{~mm}$ imidazole). The rXlCSF-1 was eluted in fractions using $250 \mathrm{mM}$ imidazole. The purity of the eluted fractions was confirmed by silver stain and the presence of rXlCSF-1 assessed by Western blot against the V5 epitope on rXICSF-1. Fractions containing $\mathrm{rXlCSF}-1$ were pooled and the protein concentration determined by the Bradford protein assay (BioRad). A protease inhibitor cocktail (Roche) was added to the purified rXlCSF-1 and the protein aliquoted and stored at $4{ }^{\circ} \mathrm{C}$ until use.

The vector control was produced by transfecting $\mathrm{Sf} 9$ cells in parallel to the $\mathrm{rXlCSF}-1$ production, but with an empty expression vector, and the methodology described for the generation and isolation of $\mathrm{rXlCSF}-1$.

\section{Cell Culture Medium}

The ASF culture medium used in these studies has been reported previously [17]. All cell cultures were established using ASF supplemented with $10 \%$ fetal bovine serum, $2.5 \%$ heat-inactivated $X$. laevis serum, $20 \mu \mathrm{g} / \mathrm{ml}$ kanamycin and $100 \mathrm{U} / \mathrm{ml}$ penicillin $/ 100$ $\mu \mathrm{g} / \mathrm{ml}$ streptomycin (Gibco). Amphibian PBS (APBS) has been described previously [17].

\section{Isolation of X. laevis Subcapsular Liver and Bone Marrow} Cells

Immediately after euthanasia, frog livers were aseptically removed, the liver peripheries peeled off, and the cells isolated by gently passing through a sterile nylon mesh. Liver cells were layered over 51\% Percoll (Sigma)/49\% APBS and centrifuged at $400 \mathrm{~g}$ at $4^{\circ} \mathrm{C}$ for $25 \mathrm{~min}$ to separate out red blood cells and debris. The leukocyte-containing interfaces were removed and washed with ice-cold APBS prior to culture. Frog femurs were aseptically removed, flushed with $10 \mathrm{ml}$ of ice-cold APBS each $(50 \mathrm{U} / \mathrm{ml}$ heparin; Lancaster, and $100 \mathrm{U} / \mathrm{ml}$ penicillin $/ 100 \mu \mathrm{g} / \mathrm{ml}$ streptomycin; Gibco) and washed with ice-cold APBS prior to culture. Cultures were cytospun (Shandon Southern), Giemsa stained and images derived using an Axiovert 200 inverted microscope and Infinity 2 digital camera (objective: 40/0.6; Zeiss). Digital images were analyzed using the Image-Pro Plus software.

\section{rXlCSF-1 Cell Stimulation and Flow Cytometry}

For differentiation experiments, $5 \times 10^{4} X$. laevis liver periphery and bone marrow cells were incubated at $27^{\circ} \mathrm{C}$ in individual wells of 48 -well plates with $\mathrm{rXlCSF}-1(1,100 \mathrm{ng} / \mathrm{ml})$ or equal volumes of vector control. Subsequently, cells were washed with, and resuspended in, FACS staining buffer (APBS, 1\% BSA, $0.01 \%$ sodium azide).

For MHC class II staining experiments, bone marrow cells were incubated on ice for $1 \mathrm{~h}$ with anti-Xenopus MHC class II monoclonal antibody (AM20 [18]), washed and stained with a goat $\alpha$-mouse
FITC antibody (Sigma). Cells were again washed and analyzed by flow cytometry.

To assess $\mathrm{rXlCSF}-1$ binding, freshly isolated bone marrow and liver periphery cells were incubated with vector control, or $30 \mathrm{ng}$ or $3 \mu \mathrm{g}$ of $\mathrm{rXlCSF}-1$ in culture medium on ice for $1 \mathrm{~h}$. Cells were washed and sequentially stained with $\alpha$-V5 (Invitrogen) and goat $\alpha$-mouse FITC (Sigma) antibodies. Cells were washed and analyzed by flow cytometry.

All flow cytometry was performed on a FACSCanto II (BD) instrument using consistent instrument settings. Data analysis was performed using FlowJo software.

\section{Semisolid Medium-Based Colony-Forming Assay}

$X$. laevis liver periphery and bone marrow cells were incubated at $27^{\circ} \mathrm{C}$ for 10 days in $35 \times 10 \mathrm{~mm}$ sterile Petri dishes in culture medium containing $0.8 \%$ methylcellulose (Spectrum) and either vector control, or 1 or $100 \mathrm{ng} / \mathrm{ml}$ of $\mathrm{rXlCSF}-1$. Colonies were enumerated using a grid and an inverted microscope (objectives: 25/0.40 and 40/0.6, Vista Vision; VWR).

\section{In vitro rXlCSF-1 Cross-Linking Studies}

One microgram of $\mathrm{rXlCSF}-1$ was incubated in the absence or presence of $2.5 \mathrm{mM}$ disuccinimidyl suberate (DSS, final concentration; Therom Scientific) cross-linker for $30 \mathrm{~min}$. Cross-linking was terminated for $15 \mathrm{~min}$ with $50 \mathrm{~mm}$ Tris (final concentration). The reactions were visualized using Western blot against the V5 epitope and developed using ECL (Pierce) on X-ray film (Eastman Kodak Co.)

\section{Statistical Analysis}

Statistical analysis was performed using one-way analysis of variance (ANOVA) and Tukey's post hoc test. A probability level of $\mathrm{p}<0.05$ was considered significant. Vassar Stat was used for statistical computation (http://faculty.vassar.edu/lowry//anovalu. html).

\section{Results}

\section{Identification of the X. (Silurana) tropicalis and}

\section{$X$. laevis CSF-1}

To investigate the development of Xenopus macrophages, we sought to identify the amphibian ortholog of the central macrophage growth factor CSF-1. Since CSF1 molecules share poor identity across vertebrate species $[1,3]$, we utilized the fully sequenced $X$. tropicalis genome for gene synteny analysis to identify the X. tropicalis CSF1. Accordingly, we assessed the loci of the human (H. sapiens, chromosome 1), mouse (M. musculus, chromosome 3 ) and green anole (A. carolinensis, chromosome 4) chromosomes, bearing the CSF-1 genes of respective species (fig. 1a). These CSF-1 loci exhibited highly conserved organization surrounding the respective CSF-1 genes, with FAM40A, ACHYL1 and EPS8L3 flanking the CSF-1 gene in each case (fig. 1a). We traced these to a scaffold (NW_003163367.1) in the X. tropicalis genome, where 
Fig. 1. a Gene synteny analysis of vertebrate CSF-1. Synteny analysis of human (H. sapiens), mouse (M. musculus), green anole (A. carolinensis) and frog [X. (Silurana) tropicalis] CSF-1 loci. The abbreviated genes are: ubiquitin-like 4B (UBL4B); aristaless-like homeobox 3 (ALX3); family with sequence similarity 40, member A (FAM40A); S-adenosylhomocysteine hydrolase-like 1 (ACHYL1); epidermal growth factor receptor kinase substrate 8-like 3 (EPS8L3); glutathione S-transferase, mu 5 (GSTM5) and glutathione S-transferase, mu 1 (GSTM1). Arrows indicate the orientation of the respective genes.
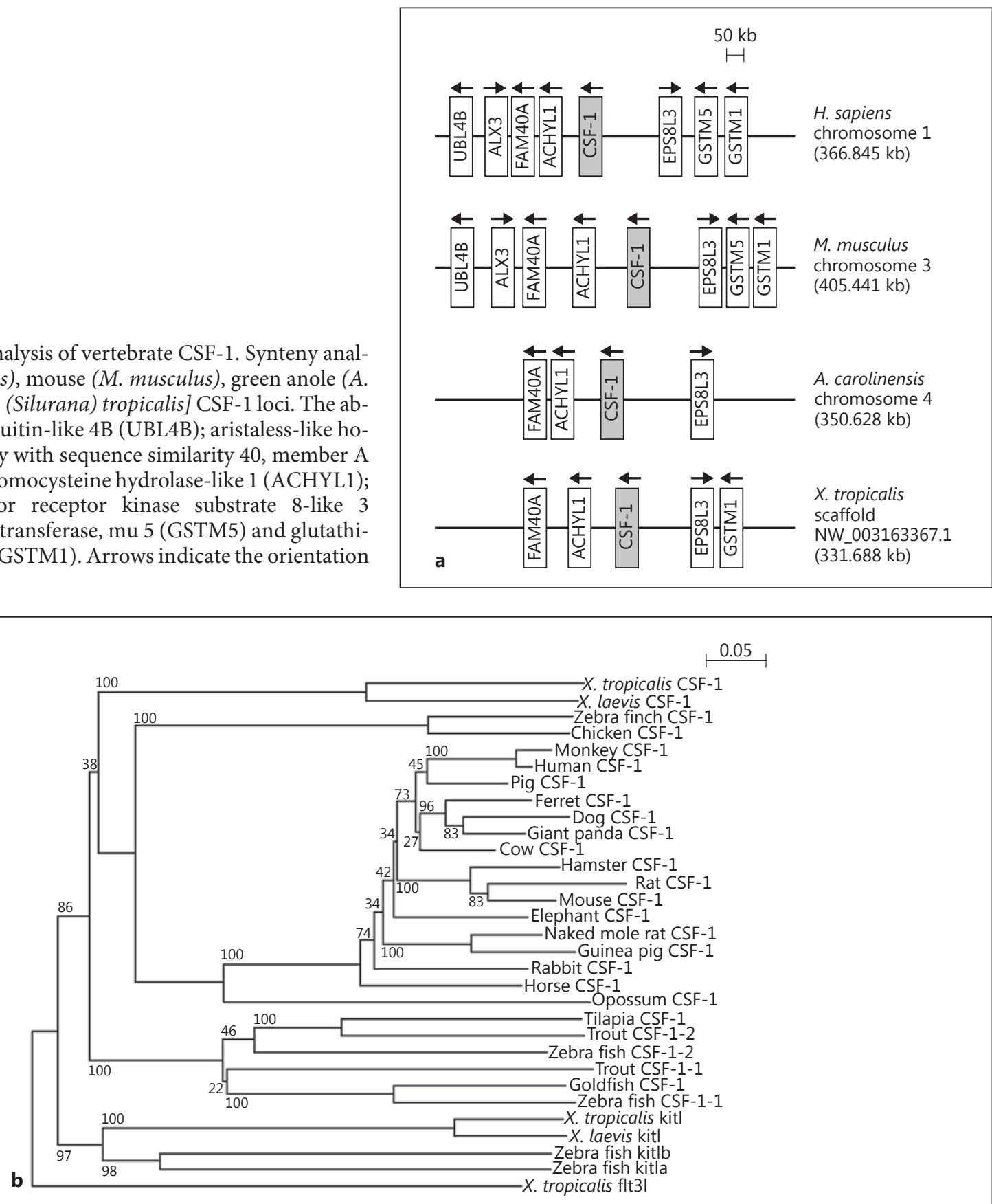

Fig. 1. b Phylogenetic analysis of vertebrate CSF-1. Phylogenetic analysis of teleost, amphibian, avian and mammalian CSF-1 proteins. The phylogenetic tree was constructed using the neighborjoining method, bootstrapped 10,000 times and bootstrap values were expressed as percentages. The $X$. tropicalis flt3l was used as an outgroup. GenBank database (accession No.): X. tropicalis CSF-1 (XP_002933042); X. laevis CSF-1 (JX418294); zebra finch CSF-1 (NM_001193261); chicken CSF-1 (NP_001180224); monkey CSF-1 (AFH31187); human CSF-1 (AAC08707); pig CSF-1 (NP_001231452); ferretCSF-1(AER96748); dogCSF-1(XP_854600); giant panda (XP_002919277); cow CSF-1 (AY274806.1); hamster
CSF-1 (EGW06541); rat CSF-1 (AAM94802); mouse (CAA28660); elephant CSF-1 (XM_003409558); naked mole rat CSF-1 (EHB07230); guinea pig CSF-1 (XP_003479261); rabbit CSF-1 (XP_00271548); horse CSF-1 (XP_001917362); opossum CSF-1 (XP_001381963); tilapia CSF-1 (XP_003438905); trout CSF-1-2 (NP_001153948); zebra fish CSF-1-2 (NP_001073545); trout CSF-11 (CAP58789); goldfish CSF-1 (CAQ42963); zebra fish CSF-1-1 (NP_001107952); X. tropicalis kitl (AAI67914); X. laevis kitl (NP_001079174); zebra fish kitlb (NP_001018137); zebra fish kitla (NP_001018133), and X. tropicalis flt31 (XP_002938571). 
Fig. 2. X. laevis CSF-1 tissue gene expression analysis. a Quantitative CSF-1 tissue gene expression analysis of tadpoles (S54), and metamorphic (S64) and adult (2-yearold) frogs; $\mathrm{n}=3$. $^{*} \mathrm{p}<0.05$. b Quantitative CSF-1 gene expression analysis of healthy and FV3-infected adult frogs (3 days after infection with $5 \times 10^{6}$ plaque-forming units of FV3); $\mathrm{n}=3$ (spleen, liver) and 6 (kidney, bone marrow). ${ }^{*} \mathrm{p}<0.05$ vs. uninfected controls. Means \pm SEM.
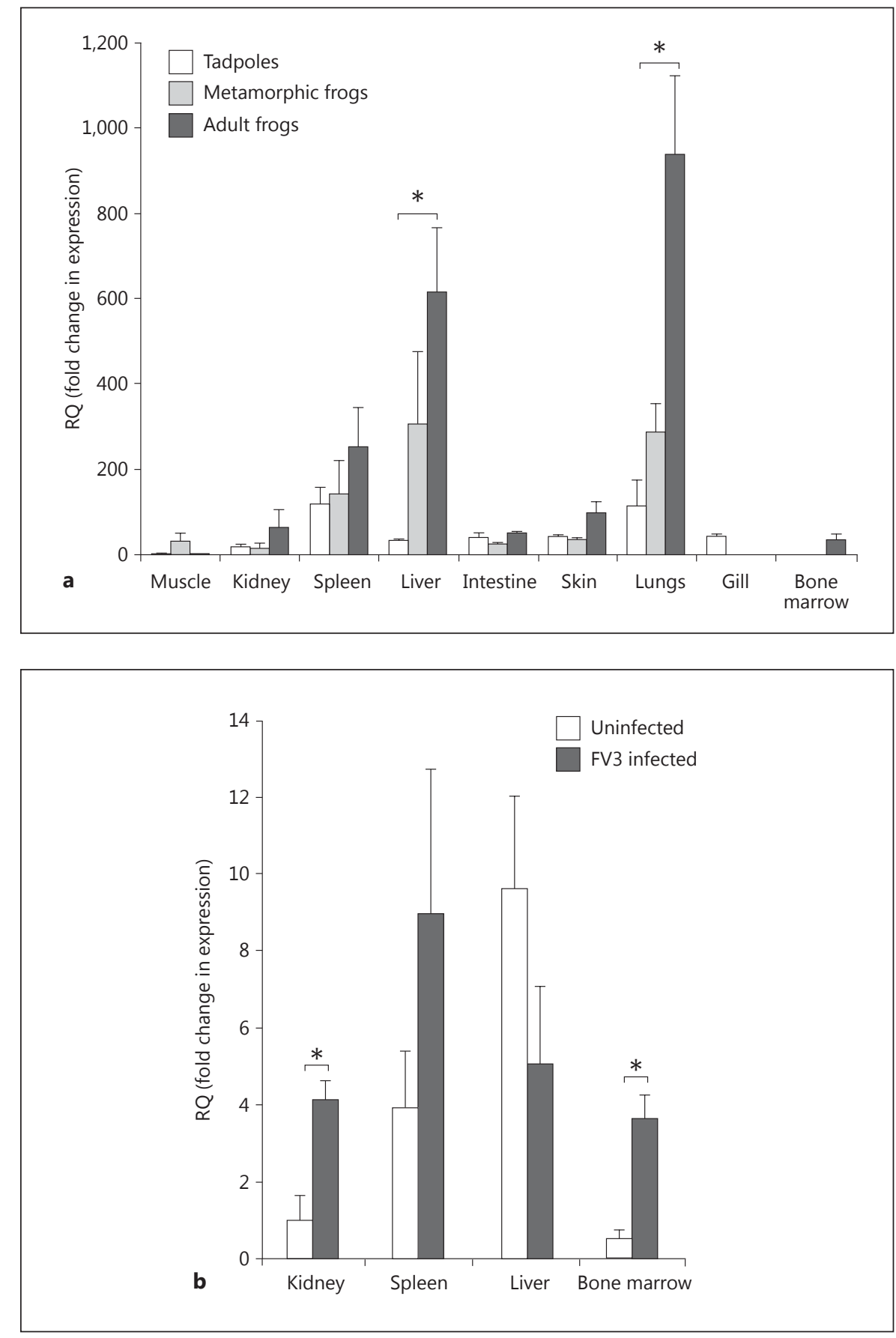

these orthologs surrounded a putative $X$. tropicalis CSF-1 gene (fig. 1a). This gene shared the greatest amino acid sequence identity with the chicken and zebra finch CSF-1 proteins, while in silico analysis revealed the presence of a single globular domain, a single transmembrane domain and conserved cysteines, characteristic of all known vertebrate CSF-1 proteins (data not shown).
We designed primers against this $X$. tropicalis CSF-1 and, via conventional and RACE PCR, we successfully identified the full cDNA transcript of the X. laevis CSF-1 (online suppl. fig. 1). The $X$. laevis transcript encodes a 258-residue protein with a signal peptide, a hallmark globular CSF-1 domain, conserved cysteines and a single transmembrane domain (online suppl. fig. 1). The $X$. 


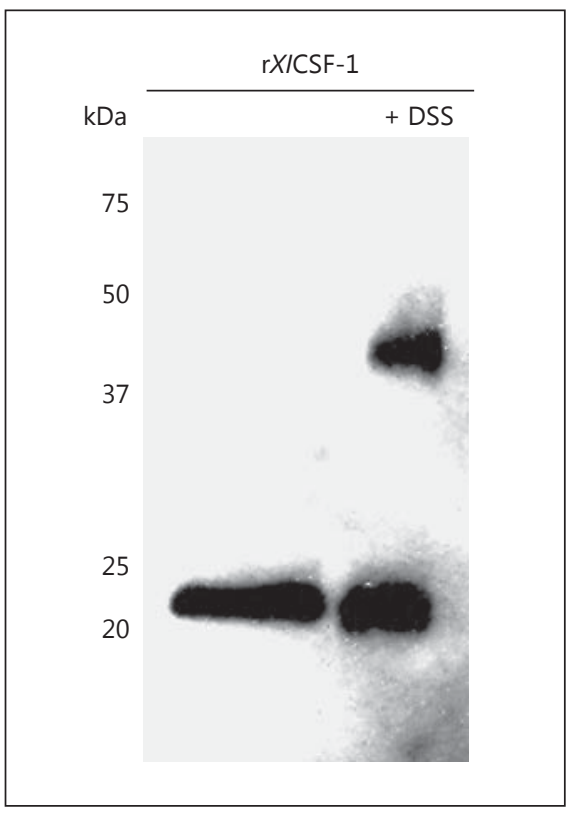

Fig. 3. In vitro cross-linking analysis of $\mathrm{rXlCSF}-1$. One microgram of $\mathrm{rXlCSF}-1$ was incubated in the absence or presence of $2.5 \mathrm{mM}$ DSS (final concentration) cross-linker for $30 \mathrm{~min}$ and visualized using Western blot against the V5 epitope.

laevis cDNA transcript exhibits a long $3^{\prime}$-untranslated region with 5 mRNA instability motifs (ATTTA) $[19,20]$ and an unconventional polyadenylation signal (AATATA; online suppl. fig. 1).

To examine the evolutionary relationships among vertebrate CSF-1 proteins, we performed phylogenetic analyses (fig. 1b). The CSF-1 of X. tropicalis and X. laevis branched closest together and independently of the other vertebrate CSF-1s (fig. 1b). The amphibian CSF-1 proteins were phylogenetically ancestral to the avian and mammalian CSF-1 molecules, albeit with a low bootstrap value (38\%, fig. $1 \mathrm{~b})$. The teleost CSF-1s branched ancestral to the amphibian, avian and mammalian molecules while the related fms-like-tyrosine-3 ligand of X. tropicalis (flt3l) was used as an outgroup (fig. 1b).

\section{Quantitative X. laevis CSF-1 Gene Expression}

Analysis in Tissues of Healthy and FV3-Infected Frogs

We performed quantitative gene expression analysis of X. laevis CSF-1 in tissues of tadpoles, and metamorphic and adult frogs (fig. 2a). In comparison to adult frogs, tadpoles generally exhibited lower CSF-1 transcript levels and distinct expression patterns, whereas animals undergoing metamorphosis (stage 64) displayed relatively intermediate CSF-1 expression levels (fig. 2a). In tadpoles,
CSF-1 mRNA levels were highest in the spleen tissues, and modestly increased with frog development (fig. 2a). While tadpoles possessed relatively low liver and lung CSF-1 transcript levels, adult frogs exhibited significantly increased CSF-1 mRNA levels in these tissues (fig. 2a). Interestingly, whereas tadpoles and adults displayed very low CSF-1 gene expression in skeletal muscle, frogs undergoing metamorphosis had elevated CSF-1 mRNA levels in regressing tail muscle tissues (fig. 2a), corroborating macrophage involvement in this process [21].

To assess possible changes in X. laevis CSF-1 gene expression following immunological challenge, we examined the expression of this gene in immunorelevant tissues of adult frogs infected for 3 days with the amphibian viral pathogen FV3 (Ranavirus, Iridoviridae; fig. 2b). Consistent with our prior work, which strongly implicated the frog kidney as the primary site of ranaviral replication [17], FV3 infection significantly increased CSF-1 transcript levels in kidney tissues of infected animals (fig. 2b). Surprisingly, CSF-1 gene expression was also significantly elevated in the bone marrow of virally infected frogs (fig. 2b). Notably, although the kidneys of infected animals exhibited high viral gene expression and the presence of large quantities of the FV3 genome, the bone marrow of infected frogs did not possess substantial viral infiltration or viral gene expression (online suppl. fig. 2). CSF-1 gene expression in the liver and spleen tissues was not significantly altered by FV3 infections (fig. 2b).

\section{Production and in vitro Cross-Linking Analysis of the rXlCSF-1}

To identify $X$. laevis macrophage precursor population(s) and to characterize the differentiation of these cells in vitro, we produced a recombinant form of the extracellular region of $X$. laevis CSF-1 protein (rXlCSF-1) using an insect protein expression system. This $\mathrm{rXlCSF}-1$ possessed $\mathrm{His}^{6}$ and $\mathrm{V} 5$ epitopes for efficient protein purification and Western blot analysis, respectively.

Since all vertebrate CSF-1 proteins function as homodimers, we wanted to confirm that the insect-expressed $\mathrm{rXlCSF}-1$ was capable of dimerization in solution. Accordingly, rXlCSF-1 was incubated in APBS in the absence (lane 1) or presence (lane 2) of the chemical cross-linker DSS (fig. 3). The reactions were then resolved by SDS-PAGE and visualized by Western blot against the V5 epitope on $\mathrm{rXlCSF}$-1. The non-cross-linked $\mathrm{rXlCSF}-1$ resolved as a monomer of roughly $22 \mathrm{kDa}$, whereas the DSS cross-linked product exhibited an additional band, indicative of $\mathrm{rXlCSF}-1$ dimerization (fig. 3, lanes 1 and 2, respectively). 


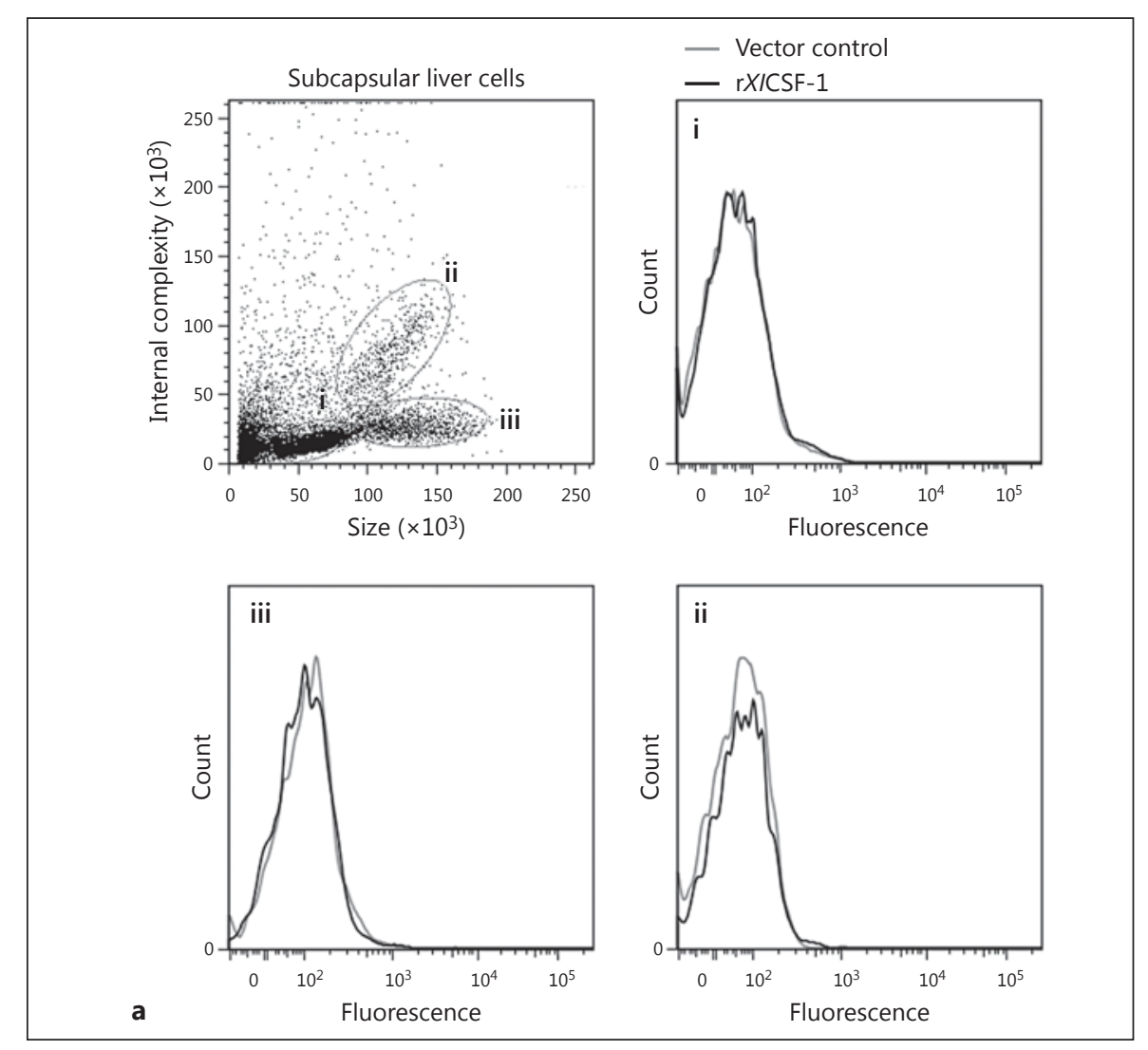

Fig. 4. Analysis of the ability of $\mathrm{r} X \mathrm{CSSF}-1$ to bind $X$. laevis subcapsular liver and bone marrow cell populations. $\alpha-\mathrm{V} 5$ staining and FACS analysis of $\mathrm{rXlCSF}-1$ binding to liver periphery (a; $3 \mu \mathrm{g})$ and bone marrow (b; $30 \mathrm{ng}, 3 \mu \mathrm{g}$ ) populations. For both peripheral liver and bone marrow cells presented in the scatter plots, the subpopulations are gated and labeled as i, ii and iii, where the panels corresponding to each numeral (i, ii and iii) represent the fluorescence profiles emitted by the respective gated populations.

Amphibian Macrophage Precursors Reside in the Nonhematopoietic Bone Marrow
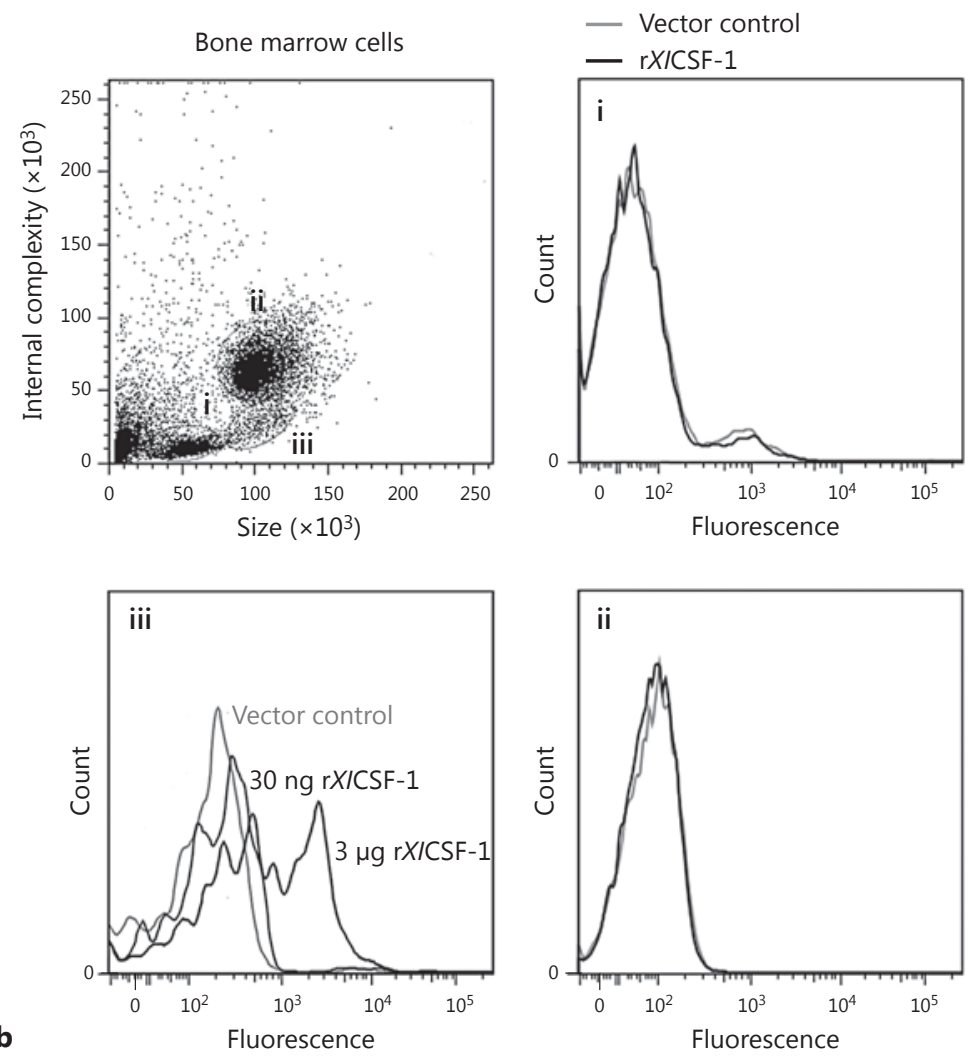


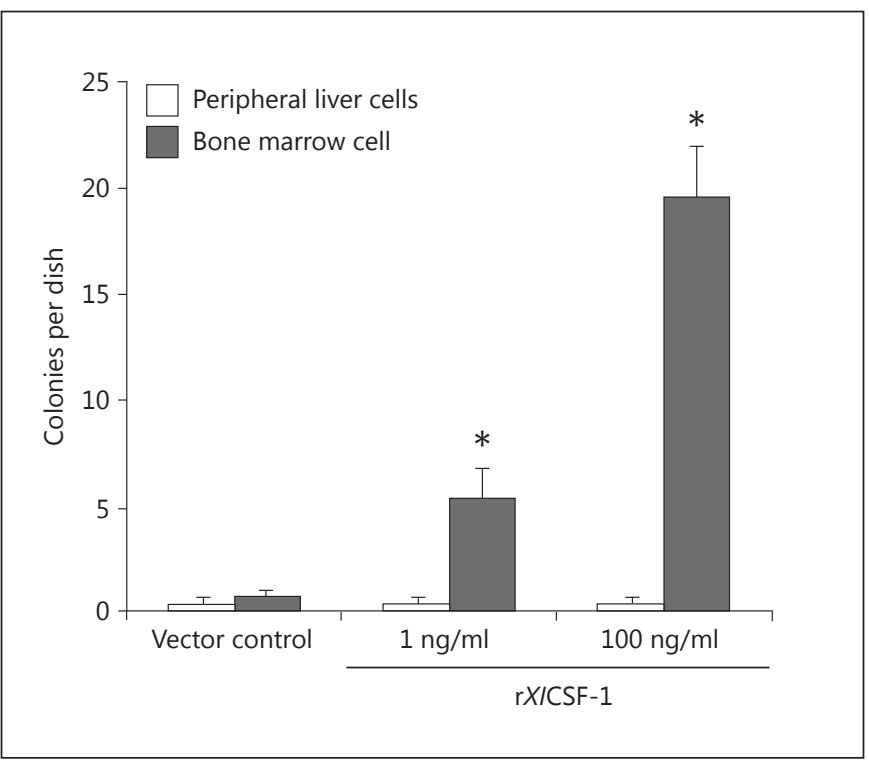

Fig. 5. Assessment of rXlCSF-1-elicited colony formation of liver periphery and bone marrow cells. $X$. laevis subcapsular liver and bone marrow cells were incubated at $27^{\circ} \mathrm{C}$ for 10 days in culture medium containing $0.8 \%$ methylcellulose and either vector control, or 1 or $100 \mathrm{ng} / \mathrm{ml}$ of $\mathrm{rXlCSF}-1$. Colonies were enumerated using a grid and an inverted microscope and are presented as means \pm SEM, $\mathrm{n}=3,{ }^{*} \mathrm{p}<0.05$.

Analysis of rXlCSF-1 Binding by X. laevis Subcapsular Liver and Bone Marrow Cell Populations

Because the subcapsular zone of the amphibian liver is believed to be the primary source of hematopoietic progenitor populations, we isolated these cells from adult frogs and examined (by flow cytometry) the capability of these cells to bind $\mathrm{rXlCSF}-1$ (fig. 4a). Additionally, since more evolutionarily advanced vertebrates utilize bone marrow as the primary source of macrophage precursors and because we observed increased bone marrow CSF-1 gene expression following FV3 infections (fig. 2b), we also examined the capacity of healthy $X$. laevis adult bone marrow cells to bind the recombinant growth factor (fig. $4 \mathrm{~b}$ ). In the absence of antibody specific against $X$. laevis CSF-1, we used an antibody against the V5 tag of rXlCSF-1. When freshly isolated peripheral liver cells from adult frogs were incubated with $\mathrm{rXlCSF}-1$, stained with $\alpha-\mathrm{V} 5$ and goat $\alpha$-mouse FITC antibodies for the recombinant protein and analyzed by flow cytometry, no fluorescence above vector control levels was observed, regardless of the cell subpopulation gated on and examined (fig. 4a). In marked contrast to the subcapsular liver cells, a subpopulation of relatively large, noncomplex bone marrow cells (fig. 4b, panel iii) clearly bound to $\mathrm{rXlCSF}-1$, as evidenced by increased fluorescence intensity. Furthermore, this binding was concentration dependent (fig. $4 \mathrm{~b}$, panel iii). These results are representative of 2 independent experiments, each using cells from 3 different frogs. The intensity of the positive signal, as well as its cell population (bone marrow but not liver cells) and concentration dependency, all strongly suggests that $\alpha$-V5 detects the specific interaction of $\mathrm{rXlCSF}-1$ with its receptor.

\section{Analysis of Colony Formation by rXlCSF-1-Stimulated} $X$. laevis Subcapsular Liver and Bone Marrow Cells

To substantiate our observations that the $X$. laevis bone marrow cells, but not subcapsular liver cells, are capable of binding and presumably responding to $\mathrm{rXlCSF}$-1, we performed a proliferation/colony formation assay using methylcellulose-based semisolid medium (fig. 5). Cells were isolated from the liver subcapsular zone and from the bone marrow of adult frogs, and cultured in $0.8 \%$ methylcellulose semisolid medium with the vector control, or 1 or $100 \mathrm{ng} / \mathrm{ml}$ of $\mathrm{rXlCSF}-1$. The above treatment conditions had no observable effects on the colony formation of the subcapsular liver cells (fig. 5). By contrast, $\mathrm{rXlCSF}-1$ treatment of bone marrowderived cells elicited significant and concentration-dependent increases in colony formation (fig. 5). These rXlCSF-1-induced bone marrow cell colonies were composed of large $(>10 \mu \mathrm{m})$, homotypic cells, suggesting that these colonies potentially comprised macrophage lineage cells. The total cell counts of the subcapsular liver and bone marrow liquid cell cultures corroborated the above findings, where, regardless of treatment, total numbers of peripheral liver cells were unchanged whereas the numbers of cultured bone marrow cells markedly increased with increasing concentrations of rXlCSF-1 (online suppl. fig. 3).

\section{Assessment of rXlCSF-1-Mediated Macrophage}

Differentiation of X. laevis Bone Marrow and

\section{Subcapsular Liver Cells}

Mammalian macrophages require concentrations of around $1,000 \mathrm{U} / \mathrm{ml}$ for maximal proliferation [22], which translate to high concentrations (in $\mathrm{ng} / \mathrm{ml}$ ) [23]. In accordance with this and the observations described above, we cultured the $X$. laevis subcapsular liver and bone marrow cells with either vector control or $100 \mathrm{ng} / \mathrm{ml}$ of $\mathrm{rXlCSF}-1$ and examined the effects of these treatments on culture cell compositions by flow cytometry (fig. 6a). Consistently and regardless of treatment, no observable differences were seen with subcapsular liver cell cultures (fig. 6a, top 
Fig. 6. $\mathrm{rXlCSF}$-1-mediated differentiation of $X$. laevis hepatic periphery and bone marrow cell populations. a FACS analysis of peripheral liver and bone marrow cells after 6 days of culture with vector control or rXlCSF-1 (100 ng/ml). b Giemsa staining and analysis of bone marrow cells after 6 days of culture with vector control or rXlCSF-1 (100 ng/ml). c CSF-1R quantitative gene expression analysis in freshly isolated and $\mathrm{rXlCSF}$-1-derived bone marrow cells. Means \pm SEM, $\mathrm{n}=6,{ }^{*} \mathrm{p}<0.05$.
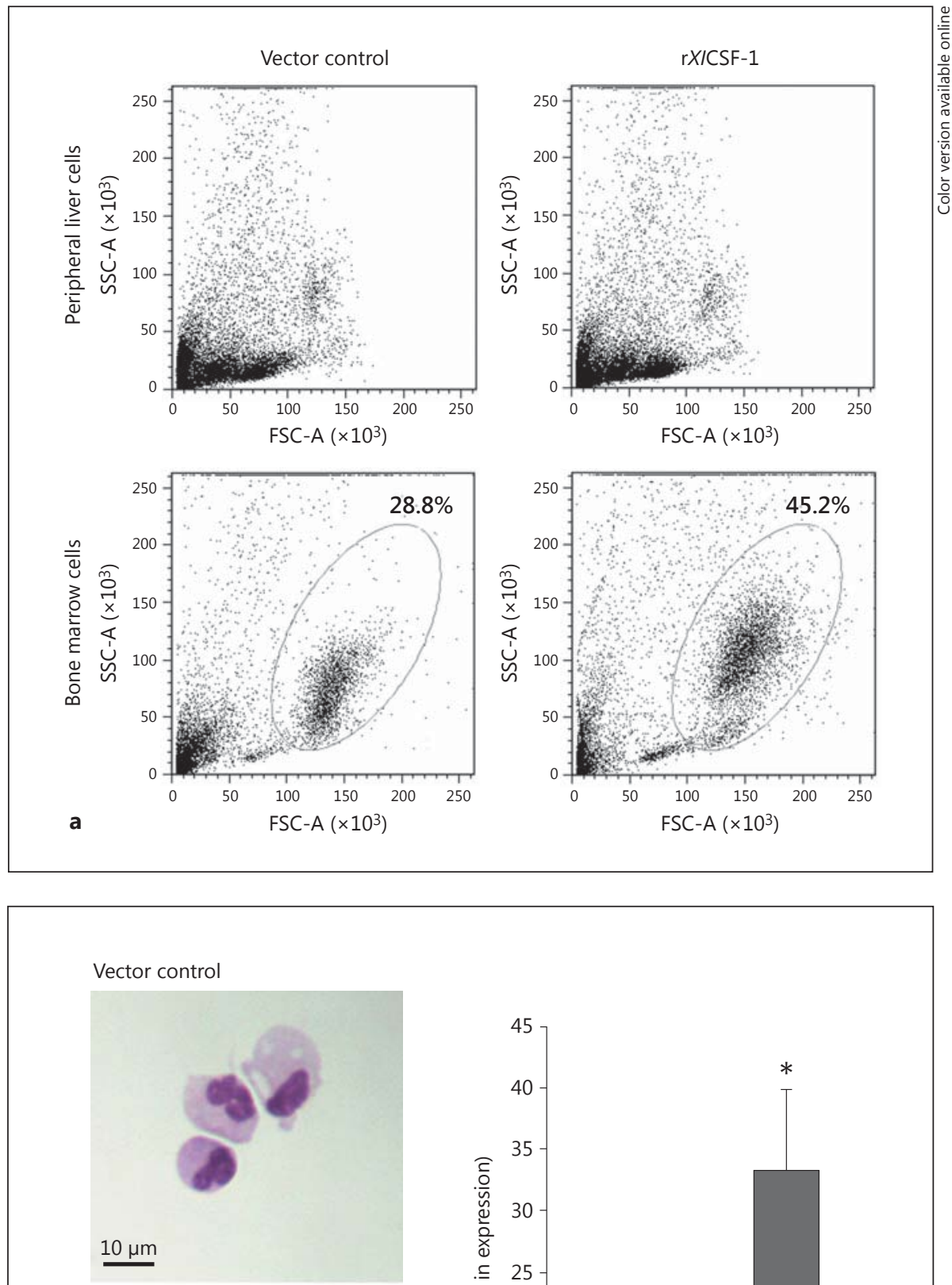

$100 \mathrm{ng} / \mathrm{ml} \mathrm{rXICSF-1}$

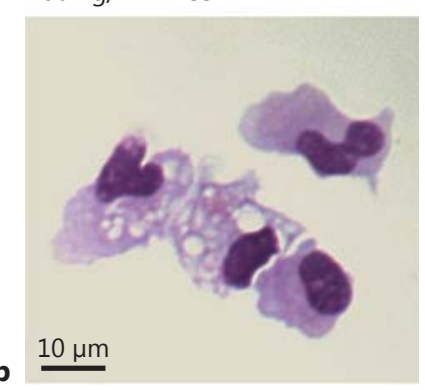

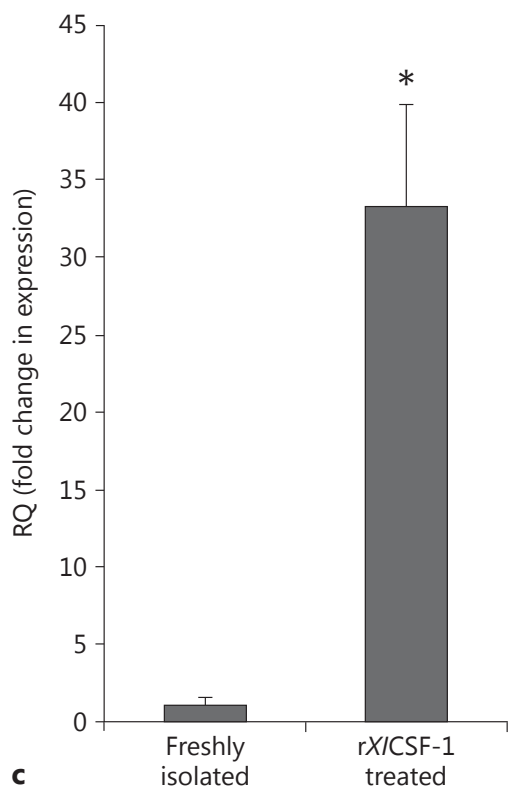


panels), whereas intermittent culture times also resulted in no observable differences (data not shown). In contrast, flow-cytometric analysis of control-treated bone marrow cell cultures revealed a population of relatively large cells, while the parallel, rXlCSF-1-treated cultures contained greater proportions of these cells ( $28.8 \%$ vector control; 45.2\%, $\mathrm{rXlCSF}-1$ cultures), which, in comparison to controls, were larger in size and exhibited increased internal complexity (fig. 6a, bottom panels). These results are representative of 2 independent experiments, each using cells from 3 individual adult frogs. Interestingly, freshly isolated bone marrow cells (fig $4 \mathrm{~b}$ ) and rXlCSF1-derived bone marrow cultures (fig. 6a) exhibited distinct cell population profiles. Whether the addition of $\mathrm{rXlCSF}-1$ can cause an expansion of a subpopulation of cells present in low numbers in the initial primary cells isolated from the bone marrow is not known.

We examined, by microscopy, the cell morphology of bone marrow cultures treated with vector control or rXlCSF-1 and stained with Giemsa. Cultures incubated with the vector control (fig. 6b, top panel) or in medium alone (data not shown) consisted primarily of mononuclear cells with large cytoplasms and very characteristic phagocyte morphology. Strikingly, cultures that had been incubated with $\mathrm{rXlCSF}-1$ comprised much larger cells, exhibiting extensive vacuolation and membrane ruffling (fig. 6b, bottom panel), consistent with the hallmark characteristics of CSF-1-differentiated macrophages [22].

To confirm that the $\mathrm{rXlCSF}$-1-derived bone marrow cultures contained macrophage lineage cells, we cloned a fragment of the $X$. laevis CSF-1R cDNA and compared its gene expression in freshly isolated and $\mathrm{rXlCSF}-1$-incubated bone marrow cell cultures (fig. 6c). The rXlCSF1-derived cultures displayed significantly increased CSF$1 \mathrm{R}$ expression (fig. 6c), corroborating the responsiveness of these cells to the cognate CSF-1 ligand.

To further assess the rXICFS-1-elicited differentiation of bone marrow cultures, we examined, by flow cytometry, the MHC class II surface expression on these cells. Bone marrow cells from the control cultures comprised a large and complex population that stained low for class II, and a population of large but relatively less-complex cells with high class II staining (online suppl. fig. 4, left panels). Interestingly, the $\mathrm{rXlCFS}$-1-derived cultures were comprised of a larger, more complex, class II population with low staining as well as an increased proportion of large cells with class II high staining, some, but not all of which exhibited increased granularity (online suppl. fig. 4, right panels).

\section{Discussion}

This is the first report detailing macrophage development of an anuran, as well as the first identification of an amphibian CSF-1. The synteny surrounding this vertebrate gene has been extremely well conserved, enabling the identification of the X. tropicalis CSF-1. It should be noted that while birds and mammals possess a single, alternatively spliced CSF-1 [24, 25], fish possess 2 distinct CSF-1 genes that do not appear to be alternatively spliced [1]. It is unknown whether the distinct fish CSF-1s assume the roles conferred by the mammalian CSF- 1 variants. Although the 2 zebrafish CSF-1 genes are located on distinct chromosomes, each flanked by some of the genes syntenic to the single mammalian CSF-1, we traced several of these segregated genes to a single $X$. tropicalis gene scaffold, negating the existence of an additional anuran CSF-1 (data not shown). In addition, we were unable to identify alternatively spliced $X$. laevis CSF-1 transcripts through either conventional or RACE PCR, using a range of cDNA templates from healthy and immunologically challenged tadpoles and adults (data not shown). Although we cannot rule out the possibility of either an additional or alternatively spliced Xenopus CSF-1, our results suggest the absence of both. Notably, the N-terminal 150 residues of mammalian CSF-1s are sufficient for activity $[26,27]$, while amphibians are evolutionarily intermediate between teleosts and mammals, which exhibit 2 unspliced and 1 alternatively spliced CSF-1, respectively. Our results suggest that the Xenopus macrophage development strategies are different to those seen in other vertebrates. Possibly, these distinctions dictate the requirement for a single, membrane-bound Xenopus CSF-1, with more stringent enzymatic release into the extracellular milieu.

Our gene expression studies revealed greatest CSF-1 transcript levels in adult liver and lung tissues, and elevated kidney and bone marrow CSF-1 mRNA levels following FV3 infections. Perhaps the increased bone marrow and kidney CSF-1 expression evince increased production of macrophages and their recruitment to infection sites, respectively. Mammalian CSF-1 is responsible for the maintenance of alveolar macrophages [28] whereas the viability of Kupffer cells and liver integrity are interdependent of CSF-1 [29]. Presumably, the above is reflected in the high CSF-1 expression in X. laevis liver and lung tissues.

The surface expression of CSF-1R on progenitor cell populations is considered the hallmark of the commitment to the macrophage lineage [30] where the mRNA 
and protein levels of CSF-1R increase to detectable levels from macrophage colony-forming units through macrophage development and maturation [31-33]. Prior to this commitment, CSF-1 stimulation is insufficient to drive progenitors down macrophage differentiation pathways, where CSF-1 acts in synergism with factors like kit ligand and interleukin-3 to influence pluripotent progenitors towards the mononuclear phagocyte lineage $[8,9]$. Subsequent to the commitment and in coordination with increased CSF-1R expression, these cells become responsive to CSF-1 stimulation and differentiate along macrophage pathways $[34,35]$. Pluripotent stem cells and cell commitment occur in hematopoietic organs such as the avian and mammalian bone marrow $[4,22]$ and the teleost head kidney $[10,11]$. Interestingly, although the Xenopus subcapsular liver clearly functions as the primary site of hematopoiesis $[13,14,36]$, our findings strongly suggest that committed macrophage precursor populations are located in the Xenopus bone marrow. Notably, where macrophage lineage commitment is defined by responsiveness to CSF-1, rXlCSF-1-stimulated bone marrow cells proliferated, formed colonies and differentiated into cells with classic macrophage morphology and high CSF-1R expression. In contrast, $\mathrm{rXlCSF}-1$ treatment of subcapsular liver cells had no observable effects. Furthermore, whereas a distinct bone marrow cell population exhibited $\mathrm{rXlCSF}-1$ binding, no such interactions were seen with cells derived from the subcapsular liver.

It is worth reiterating that while the Xenopus bone marrow is relatively rudimentary, it has been confirmed as the site of granulocyte differentiation/storage $[13,14]$. Indeed, we have observed a large number of polymorphonuclear granulocytes amongst the freshly isolated bone marrow cells (data not shown). However, after several days of culture, we observed substantially fewer/no polymorphonuclear cells in the bone marrow cultures (regardless of $\mathrm{rXlCSF}-1$ treatment, data not shown), reflected by the decreased total numbers of bone marrow cells recovered with culture time. Possibly, as in mammals, short-lived mature granulocytes are also stored in the Xenopus bone marrow. Presumably and for physiological reasons beyond our speculation, Xenopus mononuclear phagocytes may originate from subcapsular liver-derived pluripotent stem cells and subsequently mature and reside in the amphibian bone marrow. Since freshly isolated and rXlCSF-1-derived bone marrow cultures exhibited distinct cell population profiles, it is possible that the bone marrow macrophage precursors are initially present in low proportions but live longer than the granulocytes and are otherwise expanded by $\mathrm{rXlCSF}-1$. The relatively small proportion of bone marrow cells staining positive for bound $\mathrm{rXlCSF}-1$ is consistent with this possibility.

While macrophages and granulocytes display partially overlapping gene expression profiles, including transcriptional regulation of CSF-1R, only mononuclear phagocytes but not granulocytes possess surface protein expression of this receptor [37]. Unfortunately, the present work has been limited by the absence of an anti-Xenopus CSF-1R antibody, preventing us from confirming CSF-1R protein expression in the $\mathrm{r} X \mathrm{CSSF}-1$-derived macrophage cultures. However, by means of several distinct assays, we have observed that a population of Xenopus bone marrow cells respond to the $\mathrm{rXlCSF}-1$ and differentiate into cultures of primarily large mononuclear cells with very characteristic macrophage morphology. Thus, although we do not have direct evidence that the increased expression of CSF-1R in $\mathrm{rX}$ CCSF-1-derived bone marrow cultures is paralleled by surface protein expression of this receptor, we are fairly confident that the resulting cell types are mainly mononuclear lineage phagocytes.

Our findings regarding the source of committed Xenopus macrophage precursors are notable in comparison to what has been seen in all other vertebrate species studied to date. The distinct physiology and/or ecological pressure of this organism likely dictate the Xenopus macrophage development pathways. Notably, the more terrestrial amphibians such as the Rana genus utilize the bone marrow for erythropoiesis [38] whereas this process undeniably occurs in the Xenopus liver periphery [15]. Possibly, the use of the bone marrow for blood cell development has occurred in stages throughout evolution. Further investigations into the macrophage lineage developmental strategies utilized by different amphibian species could well lead to a better understanding of the evolution and the complexities of these pathways in all vertebrates.

\section{Acknowledgments}

We thank Tina Martin and David Albright for animal husbandry. We thank Drs. Nicholas Cohen and Eva-Stina Eldhom for their critical review of this paper. This research was supported by R24-AI-059830 and IOB-074271 grants from the National Institutes of Health and the National Science Foundation, respectively. L.G. was supported by a postdoctoral fellowship from the National Sciences and Engineering Research Council of Canada. 


\section{References}

$>1$ Wang T, Hanington PC, Belosevic M, Se- 15 Nogawa-Kosaka N, Sugai T, Nagasawa K, Tacombes CJ: Two macrophage colony-stimulating factor genes exist in fish that differ in gene organization and are differentially expressed. J Immunol 2008;181:3310-3322.

$\checkmark 2$ Pixley FJ, Stanley ER: CSF-1 regulation of the wandering macrophage: complexity in action. Trends Cell Biol 2004;14:628-638.

$>3$ Hanington PC, Wang T, Secombes CJ, Belosevic M: Growth factors of lower vertebrates: characterization of goldfish (Carassius auratus L.) macrophage colony-stimulating factor-1. J Biol Chem 2007;282:31865-31872.

4 Garceau V, Smith J, Paton IR, Davey M, Fares MA, Sester DP, Burt DW, Hume DA: Pivotal advance: avian colony-stimulating factor 1 (CSF-1), interleukin-34 (IL-34), and CSF-1 receptor genes and gene products. J Leukoc Biol 2010;87:753-764.

$\checkmark 5$ Dai XM, Ryan GR, Hapel AJ, Dominguez MG, Russell RG, Kapp S, Sylvestre V, Stanley ER: Targeted disruption of the mouse colonystimulating factor 1 receptor gene results in osteopetrosis, mononuclear phagocyte deficiency, increased primitive progenitor cell frequencies, and reproductive defects. Blood 2002;99:111-120.

6 Lichanska AM, Browne CM, Henkel GW, Murphy KM, Ostrowski MC, McKercher SR, Maki RA, Hume DA: Differentiation of the mononuclear phagocyte system during mouse embryogenesis: the role of transcription factor PU.1. Blood 1999;94:127-138.

$>7$ Guilbert LJ, Stanley ER: Specific interaction of murine colony-stimulating factor with mononuclear phagocytic cells. J Cell Biol 1980;85 153-159.

-8 Bartelmez SH, Bradley TR, Bertoncello I, Mochizuki DY, Tushinski RJ, Stanley ER, Hapel AJ, Young IG, Kriegler AB, Hodgson GS: Interleukin 1 plus interleukin 3 plus colonystimulating factor 1 are essential for clonal proliferation of primitive myeloid bone marrow cells. Exp Hematol 1989;17:240-245.

$>9$ Kriegler AB, Verschoor SM, Bernardo D, Bertoncello I: The relationship between different high proliferative potential colony-forming cells in mouse bone marrow. Exp Hemato 1994; $22: 432-440$

-10 Belosevic M, Hanington PC, Barreda DR: Development of goldfish macrophages in vitro. Fish Shellfish Immunol 2006;20:152-171.

-11 Neumann NF, Barreda DR, Belosevic M: Generation and functional analysis of distinct macrophage sub-populations from goldfish (Carassius auratus L.) kidney leukocyte cultures. Fish Shellfish Immunol 2000;10:1-20.

$\checkmark 12$ Chen XD, Turpen JB: Intraembryonic origin of hepatic hematopoiesis in Xenopus laevis. J Immunol 1995;154:2557-2567.

13 Hadji-Azimi I, Coosemans V, Canicatti C: Atlas of adult Xenopus laevis laevis hematology. Dev Comp Immunol 1987;11:807-874.

$>14$ Hadji-Azimi I, Coosemans V, Canicatti C: Blymphocyte populations in Xenopus laevis. Dev Comp Immunol 1990;14:69-84. nizaki Y, Meguro M, Aizawa Y, Maekawa S, Adachi M, Kuroki R, Kato T: Identification of erythroid progenitors induced by erythropoietic activity in Xenopus laevis. J Exp Biol 2011; 214:921-927.

16 Morales HD, Abramowitz L, Gertz J, Sowa J, Vogel A, Robert J: Innate immune responses and permissiveness to ranavirus infection of peritoneal leukocytes in the frog Xenopus laevis. J Virol 2010;84:4912-4922.

-17 Robert J, Abramowitz L, Gantress J, Morales HD: Xenopus laevis: a possible vector of Ranavirus infection? J Wildl Dis 2007;43: 645-652.

18 Flajnik MF, Ferrone S, Cohen N, Du Pasquier L: Evolution of the MHC: antigenicity and unusual tissue distribution of Xenopus (frog) class II molecules. Mol Immunol 1990;27: 451-462.

19 Kawasaki ES, Ladner MB, Wang AM, Van Arsdell J, Warren MK, Coyne MY, Schweickart VL, Lee MT, Wilson KJ, Boosman A, et al.: Molecular cloning of a complementary DNA encoding human macrophage-specific colony-stimulating factor (CSF-1). Science 1985; 230:291-296.

20 Bakheet T, Frevel M, Williams BR, Greer W, Khabar KS: ARED: human AU-rich elementcontaining mRNA database reveals an unexpectedly diverse functional repertoire of encoded proteins. Nucleic Acids Res 2001;29: 246-254.

21 Nishikawa A, Murata E, Akita M, Kaneko K, Moriya O, Tomita M, Hayashi H: Roles of macrophages in programmed cell death and remodeling of tail and body muscle of Xenopus laevis during metamorphosis. Histochem Cell Biol 1998;109:11-17.

-22 Tushinski RJ, Oliver IT, Guilbert LJ, Tynan PW, Warner JR, Stanley ER: Survival of mononuclear phagocytes depends on a lineage-specific growth factor that the differentiated cells selectively destroy. Cell 1982;28: 71-81.

23 Bhatnagar P, Papaioannou VE, Biggers JD: CSF-1 and mouse preimplantation develop ment in vitro. Development 1995;121:13331339.

24 Manos MM: Expression and processing of a recombinant human macrophage colonystimulating factor in mouse cells. Mol Cell Biol 1988;8:5035-5039.

25 Rettenmier CW, Roussel MF: Differential processing of colony-stimulating factor 1 precursors encoded by two human cDNAs. Mol Cell Biol 1988;8:5026-5034.

26 Taylor EW, Fear AL, Bohm A, Kim SH, Koths K: Structure-function studies on recombinant human macrophage colony-stimulating factor (M-CSF). J Biol Chem 1994;269:3117131177.

27 Koths K: Structure-function studies on human macrophage colony-stimulating factor (M-CSF). Mol Reprod Dev 1997;46:31-37, discussion 37-38.
28 Lin HS, Lokeshwar BL, Hsu S: Both granulocyte-macrophage CSF and macrophage CSF control the proliferation and survival of the same subset of alveolar macrophages. J Immunol 1989;142:515-519.

29 Amemiya H, Kono H, Fujii H: Liver regeneration is impaired in macrophage colony stimulating factor deficient mice after partial hepatectomy: the role of M-CSF-induced macrophages. J Surg Res 2011;165:59-67.

-30 Tagoh H, Himes R, Clarke D, Leenen PJ, Riggs AD, Hume D, Bonifer C: Transcription factor complex formation and chromatin fine structure alterations at the murine $\mathrm{c}$-fms (CSF-1 receptor) locus during maturation of myeloid precursor cells. Genes Dev 2002;16: 1721-1737.

-31 Bonifer C, Hume DA: The transcriptional regulation of the colony-stimulating factor 1 receptor (csf1r) gene during hematopoiesis. Front Biosci 2008;13:549-560.

32 Krysinska H, Hoogenkamp M, Ingram R, Wilson N, Tagoh H, Laslo P, Singh H, Bonifer C: A two-step, PU.1-dependent mechanism for developmentally regulated chromatin remodeling and transcription of the $\mathrm{c}$-fms gene. Mol Cell Biol 2007;27:878-887.

33 Rosa A, Ballarino M, Sorrentino A, Sthandier O, De Angelis FG, Marchioni M, Masella B, Guarini A, Fatica A, Peschle C, Bozzoni I: The interplay between the master transcription factor PU.1 and miR-424 regulates human monocyte/macrophage differentiation. Proc Natl Acad Sci USA 2007;104:1984919854.

34 Cecchini MG, Dominguez MG, Mocci S, Wetterwald A, Felix R, Fleisch H, Chisholm O, Hofstetter W, Pollard JW, Stanley ER: Role of colony stimulating factor- 1 in the establishment and regulation of tissue macrophages during postnatal development of the mouse. Development 1994;120:1357-1372.

35 Stanley ER, Chen DM, Lin HS: Induction of macrophage production and proliferation by a purified colony stimulating factor. Nature $1978 ; 274: 168-170$.

36 Lane MC, Sheets MD: Primitive and definitive blood share a common origin in Xenopus: a comparison of lineage techniques used to construct fate maps. Dev Biol 2002;248:5267.

37 Sasmono RT, Ehrnsperger A, Cronau SL, Ravasi T, Kandane R, Hickey MJ, Cook AD, Himes SR, Hamilton JA, Hume DA: Mouse neutrophilic granulocytes express mRNA encoding the macrophage colony-stimulating factor receptor (CSF-1R) as well as many other macrophage-specific transcripts and can transdifferentiate into macrophages in vitro in response to CSF-1. J Leukoc Biol 2007;82: 111-123.

38 Carver FJ, Meints RH: Studies of the development of frog hemopoietic tissue in vitro. I. Spleen culture assay of an erythropoietic factor in anemic frog blood. J Exp Zool 1977;201: 37-46. 